\title{
Müşteri Sadakatini Etkileyen Bir Araç Olarak Oyunlaştırma*
}

\author{
Kyial Baiturova ${ }^{1}$, Selda Başaran Alagöz ${ }^{2}$ \\ ${ }^{1}$ Necmettin Erbakan Üniversitesi, İşletme Bölümü, k.baiturova@gmail.com \\ ${ }^{2}$ Necmettin Erbakan Üniversitesi, Ulaştırma ve Lojistik Yönetimi Bölümü, sbalagoz@konya.edu.tr
}

\begin{abstract}
Özet
Oyunlaşıırma, insanların ilgisini çekmek için keşfedilen ve pazarlamada firmalar tarafindan sıklıkla kullanılmaya başlanan yeni bir araçtır. Oyun tasarımcıları uzun zaman içerisinde oyuncu psikolojisini dikkatle inceleyerek, oyuncuların katılımını arttırabilmek için hangi oyuncu tipinde hangi oyun unsurunun etkili olacağını belirlemektedirler. Sonuçta insanlar boş vakitlerinin büyük kısmını, bazen de uyku saatlerini bile oyunlara harcamaktadır. Bunun farkına varan pazarlamacılar oyun felsefesi ve oyun unsurlarını pazarlama amaçlarında kullanmaya başlamış̧ır.

Bugün sadece çocuklar değil, yetişkinler de yarışmayı, eğlenmeyi ve ödüllendirilmeyi istemektedirler. Bu nedenle firmalar, sadakat programları oluştururken ve halkla ilişkiler faaliyetlerini yürütürken oyunlaştırmanın önemini göz önünde bulundurmalıdırlar. Oyunlaştırmanın firmalar açısından en büyük avantajlarından birisi, kendi kullanıcılarını referans göstererek diğer kullanıcılara ve potansiyel hedef kitleye ulaşabilmeleridir. Özellikle birçok pazar bölümüne ulaşabilmek için farklı tüketicilere içerik ve kurgu bakımından uyumlu hale getirildiğinde önemli bir geri dönüş sağlanabilmektedir

Bu çalışmanın amacı; oyunlaştırmanın müşteri sadakatini arttırmada etkili olup olmadığını incelemektir. Araştırma, Kırgızistan'da başarılı firmalardan biri olan ve oyunlaștırma unsurlarını sıklıkla kullanan 'Beeline' GSM operatörü üzerinde yapılmıștır. Online ankete bu firmanın 352 müșterisi dâhil edilmiștir. Araştırmada müşterilerin karşılaştıkları oyunlaştırmaya verdikleri tepki ve firmaya olan bağımlılıklarını nasıl etkilediği çeşitli analizlerle test edilmiştir. Sonuçta oyunlaştırma aracılığıyla özel müşteri olmak isteği ve oyunlaştırma aktivitelerinin eğlenceli olması faktörünün müşteri sadakati üzerinde anlamlı ve pozitif etkiye sahip olduğu tespit edilmiştir.
\end{abstract}

Anahtar Kelimeler: Oyunlaştırma, Sosyal Medyada Oyunlaştırma, Müşteri Sadakati.

\section{Gamification As A Tool That Influences Customer Loyalty}

\section{Abstract}

Gamification is a new tool that was created to attract people's attention. You can see that this tool is increasingly used by successful companies. To achieve high interest of players, creators of computer games studied their psychology for a long time. The purpose was to determine which game elements will be effective for a particular type of player. Obviously, many creators of these games have succeeded. People spend most of their rest time for playing games, sometimes even forgetting about sleep. Marketers who noticed this trend, began to use the philosophy of the game and its elements for marketing purposes.

Today, not only children, but also adults want to compete, have fun and be rewarded. For this reason, companies should take into account the importance of gamification in loyalty programs and public relations activities. In terms of companies, one of the biggest advantages of gamification is that they can reach other users and potential target groups by referring their own users. Especially it is possible to achieve a significant return in achieving many market segments, if for different consumers there is a harmony between content and fiction.

The goal of this research is to find out whether gamification is effective in increasing customer loyalty. The research was conducted in the format of an online questionnaire. Respondents were 352 clients of one of the largest companies in Kyrgyzstan "Beeline", which successfully introduces gamification for marketing purposes. The research using various analyzes of SPSS revealed to how customers react to the gamification and whether this tool affects the loyalty to the company. As a result of this survey, it was found that the desire to be a VIP client through gamification and the entertaining nature of gamification have a positive effect on customer loyalty.

Keywords: Gamification, Gamification in Social Media, Customer Loyalty.

* Bu çalışma daha önce “International Conference on Global Competition and Innovation” kongresinde özet bildiri olarak sunulmuştur.

\section{Giriş}

Teknolojinin gelişmesi ile rekabetin güçlendiği ve ürünlerin oldukça farklılaştığı bu zamanda müşterilerin ihtiyaçlarını karşılayarak, sadakatini arttırmak gerçekten zor bir hale gelmiştir. Pazarlamacılar müşterilerin ilgilerini kendilerine çekebilmek için yeni yollar bulmaya çalışmaktadır. Bunlardan birisi de oyun teknolojilerinin oyun dışı alanlara eklenerek bir pazarlama enstrümanı olarak kullanıldığı oyunlaştırmadır.

Çoğu firmalar oyunlaştırmayı iç ve dış müşterilerin sadakatini ya da marka bilinirliliğini arttırmak için uygularken, bazı firmalar ise, özellikle dijital ortamlara yakın olan yeni neslin davranışlarını değiştirmek için kullanmaktadır. Oyunlaştırma birçok tüketicinin ilgisini çekebilen önemli bir araçtır. Bundan dolayı dünyadaki başarılı firmalar oyunlaştırma sürecinin uzun süre etkili olacağını düşünerek, bu pazarlama aracını kendi organizasyonlarında uygulayabilme imkânlarını değerlendirmektedirler. Kişinin markayla kurduğu derin duygusal bağ, yüksek düzeyde aktif katılım ve uzun süren bir ilişki olarak da tanımlanabilen oyunlaştırmanın temelinde, yarışma, hedefleme, başarma, ödüllendirme, puanlama, seviyelendirme ve benzeri insan motivasyonunu artıran unsurlar bulunmaktadir.

M2 Research Derneğine göre, on yıllık süre içerisinde sadece Amerikan şirketlerinin oyunlaştırma teknolojilerine yapmayı planladıkları yatırımların miktarının yıllık yaklaşık 3 milyar dolar olması beklenmektedir. 2010 yılına kadar 'oyunlaştırma' teriminin Google Trends'te hiç olmadığ 1 dikkate alınırsa, bu kavramın gelişme hızı daha kolay fark edilebilir (Zichermann ve Linder, 2014: 6). 
$\mathrm{Bu}$ konuda gelişmiş ülkelerde yapılan araştırmalara bakıldığında; Lucassen ve Jansen (2014)'in araştırmasına göre oyunlaştırma çoğunlukla müşteri katılımını arttırmak için kullanılmıştır. Hamari ve Koivisto'nun (2015) yaptıkları çalışmanın sonuçlarına göre ise, oyunlaştırmaya karşı tutumlar müşterin satın alma ve kullanımını devam etmeyi etkilemektedir. Bittner ve Shipper (2014)'e göre oyunlaştırma, her durumda etkili olmayabilir, ancak hedef kitlesi gençler olan ürünler için faydalı olabilir. $\mathrm{Bu}$ çalışmaların yapıldığı ülkelere kıyasla Kırgızistan'da oyunlaştırma, pazarlama aracı olarak henüz yenidir. Başarılı bir firmanın örneğinde günümüzde Kırgızistan pazarında oyunlaştırmanın ne kadar etkili olduğu incelenmiştir. Dolayısıyla bu araştırmanın hem akademisyenler hem de Kırgızistan'daki iş dünyası için katkı sağlaması beklenmektedir.

\section{Oyunlaştırma Kavramı}

Oyunlaştırma («Gamification») kavramı önceden de kullanılmasına rağmen 2010 yılında yaygınlaşmaya başlamıştır. En çok kabul gören tanımlar aşağıda verilmiştir:

- Oyunlaştırma, kullanıcının deneyimini ve katılımını arttırmak amacı ile oyun unsurlarının oyun dışı alanlarda kullanılmasıdır (Deterding ark, 2011: 2).

- Oyunlaştırma, oyun unsurlarının ve oyun mekaniklerin oyun olmayan alanlarda kullanılmasidır (Werbach ve Hunter, 2015: 20).

- Oyunlaştırma, oyun endüstrisinden puanlar, rozetler, seviyeler gibi oyun unsurlarını alarak bunları gerçek hayatta birleştirmektir. Sadakat programları ve oyun mekaniklerin en iyi karması ile kullanıcıları motive etme sürecidir (Zichermann ve Linder, 2014: 6).

- Oyunlaştırma, kullanıcı için değer yaratmak amacıyla oyun deneyimi ile beraber bir hizmet geliştirme sürecidir (Huotari ve Hamari, 2012: 19).

- Oyunlaştırma, oyun kavramının bir eylem olarak değil daha çok oyun felsefesi ve bu felsefeyi oluşturan unsurların oyun bağlamı dişında kullanılma biçimidir (Bozkurt ve Genç-Kumtepe, 2014: 148).

Belirtilen tanımlar incelendiğinde oyunlaştırmanın kullanıcıların ilgisini arttırarak, sadakat ve güdülenmesini etkilemek amacıyla kullanıldığı ve oyun dışı alanlarda da uygulandığı görülmektedir.

\section{Oyunlaştırma Unsurları}

Oyunlaştırma tasarımı, belirlenen amaca uygun bir şekilde oyunlaștırma unsurlarının bir araya getirilmesi ve koordine edilmesidir. Werbach ve Hunter (2015) «For The Win: How Game Thinking Can Revolutionize Your Business» adlı kitabında oyunlaştırma unsurlarını dinamikler, mekanizmalar ve bileşenler olarak ayırmıştır:

- Dinamikler, kontrol edilmesi gereken, ama oyuna doğrudan tanıtılmayan unsurlardır. Örneğin; hikayeleştirme, ilerleme, kısıtlamalar, duygular, ilişkiler.

- Mekanizmalar, faaliyetlere yön veren ve kullanıcıların ilgisini arttıran temel süreçlerdir. Bunlar; mücadele, iş birliği, rekabet, geri bildirim, kaynak edinimi, ödüller, sira, kazanım durum.

- Bileşenler, oyuncu ile etkileşime giren unsurlardır. Bunlar; kazanımlar, puanlar, rozetler, lider tablosu, seviyeler, takımlar, sanal eşyalar, içeriğe ulaşma, koleksiyonlar, macera, hediye, zorlu mücadeleler, sosyal grafikler.

El-Khuffash'ın (2013) yaptığı araştırmaya göre, en yaygın kullanılan unsur puandır. Araştırmaya katılan şirketlerin \%84 oyunlaştırma sürecinde puanları kullandıklarını belirtmişlerdir. Sonra sırayla mücadeleler, rozetler, liderlik tabloları, ödüller gelmektedir. Tabi ki bunlar oyunlaştırmanın önemli unsurlarıdır. Ancak oyunlaştırma sadece bu elementlerin herhangi bir işe eklenmesi değildir. Oyunlaştırma kullanıcı davranışlarının analiz edilmesini, sonuçta beklenen davranışların net olarak belirlenmesini ve kullanıcıların bu davranışa doğru yönlendirilmesini, yani tasarımın dikkatle incelenmesini gerektirmektedir (Werbech ve Hunter, 2015: 80).

Lucassen ve Jansen (2014) yaptıkları çalışmada oyunlaştırma unsurlarını pazarlama amaçları ile eşleştirmişlerdir. Sonuçlara göre oyunlaştırma unsurlarının çoğunluğu müşteri katılımını arttırmak için kullanılmıştır. Marka sadakati ile eşleştirilen promosyon ve çekilişlerin ise marka farkındalığı yaratmak için kullanıldığı belirlenmiştir. Önceden de belirtildiği gibi, oyunlaştırma unsurlarının müşteri davranışlarına ve belirtilen amaca göre seçilerek oyunlaştırma sürecine eklenmeleri gerekmektedir.

\section{D6 Oyunlaştırma Modeli}

Başarılı bir oyunlaştırma gerçekleştirebilmek için sistematik ve iyi yapılandırılmış bir tasarım sürecine ihtiyaç duyulmaktadır. Kullanıcıyı oyun projesinin merkezine yerleştirmek önemlidir. Nicholson'a (2012) göre anlamlı oyunlaştırma, kullanıcı merkezli oyun tasarım öğelerinin oyun dışı içeriklerle bütünleştirilmesidir. Kullanıcı merkezli tasarıma odaklanmanın faydaları ise tasarımcıların anlamsız veya zararlı olabilecek oyunlardan kaçınmasını sağlamaya yardımc olabilir. Böylece her karar sirasinda "Bu, kullanıcıya nasıl bir yarar sağlıyor?" sorusu sorulmalıdır.

Oyunlaştırma tasarımı yapılırken D6 Modeli esas alınmaktadır (Werbech ve Hunter, 2015: 64-74):

1. İş amaçlarının tanımlanması (Define business objectives). Şirketin misyonu söz konusu değildir, oyunlaştırmanın hangi amaç doğrultusunda yapılacağı önemlidir. Amaç net bir şekilde belirlenmemişse, çok iyi tasarlanan oyunlaştırma da başarısız olacaktır.

2. Hedef davranışların betimlenmesi (Delineate target behaviors). Oyunlaştırma sürecinin sonucunda belirlenen kazanımlara ulaşmak için kullanıcıların hangi davranışları göstermesi gerektiği tespit edilmelidir. Örneğin, kullanıcıların sitede kayıt yapması, forumda yorum bırakması, şirket hakkındaki bilgileri Twitter hesabında paylaşması, check-in yapmas1.

3. Oyuncuların tanımlanmast (Describe your players). Bir sonraki aşama oyuncuların tanımlanmasıdır. Bartle oyuncuları 4'e ayırmıştır (Bartle, 1996: 8-9):

- Başaranlar (Achievers), sadece hedeflere ulaşmaya veya kazanmaya değil aynı zamanda iyi performans göstererek ödülleri kazanmaya odaklanan oyunculardır.

- Sosyalleşenler (Socializers), diğer oyuncularla etkileşim içinde olmaya odaklanan oyunculardır. En yaygın olan oyuncu tipidir. 
- Kaşifler (Explorers), oyunun kendisine odaklanan oyunculardır. Oyundaki tüm alanları keşfetmekten ve özellikle gizli alanları bulmaktan mutlu olurlar.

- Katiller (Killers), genellikle diğer oyunculara karşı bir mücadele içerisinde olan ve başarılarını sergilemeyi seven oyuncu tipidir. Oyunu kazanmanın yanı sira oyunu kaybeden birilerini görmek isterler.

Kullanıcıların karakterlerini öğrendikten sonra onları gerçekten motive edecek unsurları daha kolay seçmek mümkündür. Oyuncu tipinin doğru belirlenmesi oyunlaştırmanın etkili olup olmamasını doğrudan etkileyecektir.

4.Aktivite döngülerinin tasarlanması (Devise activity cycles). Oyunlaştırma tasarımında iki tür etkinlik döngüsü kullanılmaktadır. Bunlar:

- Bağlılık döngüsü, oyunlaştırma sürecinde oyuncunun ne yaptığında ne olacağını, yani sistemin ona nasıl cevap vereceğini tanımlamaktadır (Tunga ve İnceoğlu, 2016: 276);

- İlerleme basamakları, oyunlaştırmanın genel akışının belirlenmesidir (Werbach ve Hunter, 2015: 72).

5.Eğlencenin Tasarlanmasl (Don't forget fun). Oyunlaştırma tasarımını yaparken sürecin kullanıcılar için eğlenceli olması gerektiğini unutmamalıdır. Bunun dışında uygulanacak alanı da dikkatle almak gerekir (Tunga ve İnceoğlu, 2016: 271). Örneğin; insanların sağlık sorunları gibi zor durumda iken yaptıkları satın almalar sırasında oyunlaştırmaya gidilemez.

6. Uygun araçların kullanılır hale getirilmesi (Deploy the appropriate tools). Son aşamada belirlenen amaç ve oyuncu tiplerine uygun oyun dinamik ve mekanizmaları oyunlaştırma sürecine dâhil edilerek oyunlaştırma tasarımı gerçekleştirilir.

\section{Oyunlaştırmanın Uygulanması}

Oyunlaştırmanın uygulanması dâhili, harici ve davranış değişikliği olmak üzere üçe ayrılmaktadır:

1.Dâhili Oyunlaştırma, firmanın iç müşterilerine yönelik yaptığı oyunlaştırma türüdür (Werbach ve Hunter, 2015: 16). Firma, oyun mekanizmalarını iş sürecine ekleyerek ve oyun atmosferini oluşturarak, çalışanların katılımını, işlerin istekli yapılmasını, iş tatmininin artmasını sağlayabilir. Gün geçtikçe büyük firmalar oyunlaştırmayı iş sürecinin tüm alanlarında sıklıkla uygulamaya çalışmaktadırlar (Markeeva, 2015: 183-186).

- Işse alım ve adaptasyon aracı olarak oyunlaştırma. Örneğin, IKEA firması adayların boş pozisyona uygunluğunu, beceri ve profesyonel bilgilerini kontrol etmek için oyun mekaniklerini içeren testleri kullanmaktadır.

- Çalışanların motivasyon aracı olarak oyunlaştırma. Rusya'da Alfa Bank çalışanları için «Alfatown» adlı oyun kurulmuştur. Sanal eşyaları satın alabilmek için çalışanlar banka hizmetlerinin satış hacmini arttırarak puanları toplamaktadırlar. Böylece Alfa Bank hem rutin işlere eğlence eklemiş hem de iş performansını arttırmıştır.

- Eğitim programlarının etkinliğini arttıran bir araç olarak oyunlaştırma. Örneğin, «Proplex» firması satış bölümündeki çalışanların müşteriler ile diyalog kurabilme yeteneklerini geliştirmek için dijital oyun şeklinde bir uygulama yapmıştır. En çok puan alanlar için hediye sertifikası verilmiştir.

- Çalışanların iş sürecine katılımlarını sağlayan araç olarak oyunlaştırma. Microsoft, yeni yazılımları lansmanları yapılmadan önce bir dizi teste tabi tutması gerekmekte ve bu test, zaten meşgul olan çalışanların iş yükünü olumsuz etkilemekteydi. Microsoft kendi sisteminde çalışanların isimlerini yayınlayarak her birine bir gelişim seti atamıştır. İndirme, yükleme, testi belirlenen sürelerde çalıştırma vb. gelişim setlerinde, görevlerin tamamlanma durumlarını gösteren ve en çok geri dönüşü sağlayan çalışanlar için bir lider tablosu oluşturarak, böylece oyunlaştırma aracılığı ile test süreçleri eğlenceli bir yarışma haline dönüştürülmüştür (http://www.dijitalajanslar.com).

İşgücü pazarında gün geçtikçe payı artan genç uzmanların çoğunluğu bilgisayar ve internet gibi teknolojilerinin yanı sıra dijital oyunlarla büyüyen G-nesline aittir. Bundan dolayı işverenlerin önemli sorunlarının birisi G-nesline ait çalışanların katılımını sağlamaktır. Oyunlaştırma, bu sorun için çözüm sunmaktadır. Ancak iş sürecinde oyunlaştırma uygulanırken, çalışanların kendine doğru manipülasyon hareketlerini hissetmemesi gerekmektedir. Çalışanların firmanın amaçlarına karşı gelmeyen kişisel amaçlara ulaşmalarına da firsat verilmelidir (Burke, 2012: 3).

2.Harici Oyunlaştırma, firmanın dış müşterilerine yönelik yaptığı oyunlaştırmadır. Firma ile müşteri arasındaki ilişkiyi geliştirmek, sadakati güçlendirmek, etkileşimi arttırmak ve sonucunda yüksek kar elde etmek için harici oyunlaştırma kullanılır (Werbach ve Hunter, 2015: 17).

- Tutundurma aracı olarak oyunlaştırma. Tüketicilere yöneliktir. Başarılı örneklerin birisi, Nike firmasının «Nike+» mobil uygulamasıdır. Kullanıcılara koşu skorlarını uygulamadan takip ederek, arkadaşlarıyla oyun üzerinden yarışma imkânı tanımaktadır. Uygulamalar içerisinde başarılı olanlar için, Nike rozetlerle ödüller ve yeni hedefler belirlenmektedir. Uygulamayı indirenlerin sayısının artmasıyla beraber ayakkabıların tüketimi de artmıştır (Şahin, 2016: 109).

- Sadakat programlarının aracı olarak oyunlaştırma. Foursquare kullanıcıları check-in yaptığı yerlerin özelliklerine veya check-in yapma sıklığına göre "Foursquare badges" bölümünde rozetler kazanabiliyorlar ve bu sosyal ağdaki rütbelerini yükseltebiliyorlar.

3.Davranış Değişikliği, topluma yararlı alışkanlıkları kazandırmak için uygulanan oyunlaştırma türüdür (Werbach ve Hunter, 2015: 17).

El-Khuffash'ın (2013) yaptığı araştırmanın sonuçlarına göre oyunlaştırma uygulamalarının \%54,4‘ü müşterilerin davranışını değiştirmeye odaklanmaktadır, harici ve dâhili oyunlaştırmaların ise sırayla $\% 25,3$ ve $\% 20,3$ oranında olduğu belirlenmiştir.

2009 yılının en popüler viral videoların biri "Piano Stairs" çalışması idi. Stockholm'deki bir metro istasyonunun merdiven basamakları piyano tuşlarına dönüştürülmüştür. Obezite sorununa dikkat çekme amacı taşıyan uygulamanın sonucunda, insanların \%66's1, yürüyen merdiven ya da asansör yerine normal merdivenleri tercih etmiştir (http://www.dijitalajanslar.com). 
Oyunlaştırma müşteri ve çalışanlara yönelik etkili enstrümanların setini sunmaktadır. Firmalar tarafindan en yaygın yapılan hata, sadece dış müşterilere odaklanan oyunlaştırma politikasını kullanmalarıdır. Tabi kısa zaman için müşterilerin memnuniyetini arttırıp iyi ilişkiler kurabilirler, ancak uzun zaman perspektifinden bakarsak firma çalışanlarına özen göstermiyorsa, sunulan hizmet kalitesinin düşük olduğundan dolayı müşterilerin sadakati azalacak ya da tamamen yok olacaktır (Moise, 2013: 29).

Oyunlaştırma, çevredeki diğer insanların görüşlerinin ve tavsiyelerinin etkisini azaltabilir. İç motivasyon ve algılanan yararlılık uyarılırsa, tüketici gerçekten ürünün tadını çıkarabilir ve başkalarından gelen olumsuz tavsiyelerden daha az etkilenebilir (Bittner ve Shipper, 2014: 398).

Oyunlaştırma pasta kreması, firma ise pasta olarak düşünülürse, pasta lezzetli olmadığında, kreması ne kadar tatlı olursa olsun problem çözülemeyecek ve müşteriler bir parça daha istemeyeceklerdir. $\mathrm{Bu}$ durumda hem pastanın hem de kremasının kalitesine dikkat etmek gerekmektedir (Zichermann ve Linder, 2014: 23).

Oyunlaştırmaların sadece ilgi çeken rozetler, yeni seviyeler ve liderlik tablosu olmadığını anlamak gerekir. Oyunlaştırma, oyun sistemini dikkate alarak, firmanın iş amaçları ve kullanıcıların potansiyeli ile yakın ilişki kurarak, kullanıcıların davranışını etkileme yeteneğidir. Özellikle yeni neslin düşüncesini etkileyebilenönemli bir araçtır.

\section{Metodoloji}

\subsection{Calıssmanın Amacı}

$\mathrm{Bu}$ çalışmanın amacı, sosyal medya hesaplarında uygulanan oyunlaştırmanın müşterilerin sadakati üzerindeki etkisini Kırgızistan'daki "Beeline" GSM operatörü özelinde incelemektir. Bu amaç doğrultusunda aşağıdaki sorulara yanıt aranmıştır:

1.Müşteriler hangi amaçla sosyal medyadaki yarışmalara katılmaktadır?

2.Katılımcıların demografik özelliklerine göre oyunlaştırmaya verdiği tepkiler farklılık gösteriyor mu?

3.Katılımcıların karşılaştıkları oyunlaştırma firmaya olan sadakati nasıl etkilemektedir?

\subsection{Yöntem}

Araştırma, Kırgızistan'da başarılı firmalardan birisi olan ve oyunlaştırma unsurlarını sıklıkla kullanan 'Beeline' GSM operatörü üzerinde yapıldı. Çalışmanın evrenini Beeline firmasının sosyal medya hesaplarındaki yarışmalara katılan internet kullanıcıları oluşturmaktadır. Örnekleme yöntemi olarak olasılıklı olmayan örneklem alma türlerinden kolayda örnekleme yöntemi seçilmiştir.

Veri toplama yöntemi olarak online anket kullanılmıștır. Anketin ilk bölümünde katılımcıların demografik özellikleri ile ilgili sorular yer almaktadır. İkinci bölümde ise katılımcıların sosyal medyadaki yarışmalara yönelik davranışını belirlemek amacıyla Conaway ve Garay'ın 'Competition and fun' ve 'Relationship and reward' ölçekleri, Hamari ve Koivisto'nun 'Oyunlaştırmaya karşı tutum’ ölçeği kullanılmıştır. Üçüncü bölümde müşterilerin sadakat düzeyini belirlemek için Anderson ve Srinisivan (2003)'ın çalışmasında yer alan ölçek kullanılmıştır.
Kullanılan ölçekler 5'li Likert tipi ölçeklerdir (1-Hiç Katılmiyorum, 5-Tamamen Katıliyorum).

Beeline firmasının sosyal medya hesaplarındaki yarışmalara katılan internet kullanıcılarına özel mesaj gönderilerek katılım sağlanmıştır. 352 kişiden toplanan anket verileri SPSS 21 programı ile analiz edilmiştir. Araştırma hipotezleri aşağıdaki şekilde oluşturulmuştur:

$\mathrm{H}_{1}$ : Oyunlaştırmaya karşı tutumun müşteri sadakati üzerinde pozitif yönde etkisi vardır.

$\mathrm{H}_{2}$ : Oyunlaştırma aracılığı ile özel müșteri olmak isteğinin müşteri sadakati üzerinde pozitif yönde etkisi vardır.

$\mathrm{H}_{3}$ : Oyunlaştırma aktivitelerinin eğlenceli olmasının müşteri sadakati üzerinde pozitif yönde etkisi vardır.

$\mathrm{H}_{4}$ : Oyunlaştırmaya karşı tutumları bakımından katılımcıların cinsiyet grupları arasında istatistiksel olarak anlamlı bir farklılık vardır.

$\mathrm{H}_{5}$ : Oyunlaştırma aracılığıyla özel müşteri olmak isteği bakımından katılımcıların cinsiyet grupları arasında istatistiksel olarak anlamlı bir farklılık vardır.

$\mathrm{H}_{6}$ : Oyunlaştırma aktivitelerinin eğlenceli olması bakımından katılımcıların cinsiyet grupları arasında istatistiksel olarak anlamlı bir farklılık vardır.

$\mathrm{H}_{7}$ : Oyunlaştırmaya karşı tutumları bakımından katılımcıların yaş grupları arasında istatistiksel olarak anlamlı bir farklılık vardir.

$\mathrm{H}_{8}$ : Oyunlaştırma aracılığıyla özel müşteri olmak isteği bakımından katılımcıların yaş grupları arasında istatistiksel olarak anlamlı bir farklılık vardır.

$\mathrm{H}_{9}$ : Oyunlaştırma aktivitelerinin eğlenceli olması bakımından katılımcıların yaş grupları arasında istatistiksel olarak anlamlı bir farklılık vardır.

$\mathrm{H}_{10}$ : Oyunlaştırmaya karşı tutumları bakımından katılımcıların eğitim düzeyi grupları arasında istatistiksel olarak anlamlı bir farklılık vardır.

$\mathrm{H}_{11}$ : Oyunlaştırma aracılığıyla özel müşteri olmak isteği bakımından katılımcıların eğitim düzeyi grupları arasında istatistiksel olarak anlamlı bir farklılık vardır.

$\mathrm{H}_{12}$ : Oyunlaştırma aktivitelerinin eğlenceli olması bakımından katılımcıların eğitim düzeyi grupları arasında istatistiksel olarak anlamlı bir farklılık vardır.

$\mathrm{H}_{13}$ : Oyunlaştırmaya karşı tutumları bakımından katılımcıların gelir düzeyi grupları arasında istatistiksel olarak anlamlı bir farklılık vardır.

$\mathrm{H}_{14}$ : Oyunlaştırma aracılığıyla özel müşteri olmak isteği bakımından katılımcıların gelir düzeyi grupları arasında istatistiksel olarak anlamlı bir farklılık vardır.

$\mathrm{H}_{15}$ : Oyunlaştırma aktivitelerinin eğlenceli olması bakımından katılımcıların gelir düzeyi grupları arasında istatistiksel olarak anlamlı bir farklılık vardır.

\subsection{Bulgular ve Yorum}

Katılımcıların demografik özellikleri Tablo 1'de özetlenmiştir.

Örneklemin \%55,7’si (196 kişi) kadın, \%44,3’ü (156 kişi) ise erkeklerden oluşmaktadır. Yaşa göre ise en büyük kısmı 21-26 yaş aralığındaki katılımcılar oluşturmaktadır $(\% 59,7)$. 
Tablo 1. Katılımcıların Demografik Özellikleri

\begin{tabular}{|c|c|c|c|c|c|c|c|}
\hline \multicolumn{2}{|c|}{ Parametreler } & \multirow{2}{*}{$\begin{array}{c}\text { Frekans } \\
196 \\
\end{array}$} & \multirow{2}{*}{$\begin{array}{c}\% \\
55,7 \\
\end{array}$} & \multicolumn{2}{|r|}{ Parametreler } & \multirow{2}{*}{$\begin{array}{c}\text { Frekans } \\
47\end{array}$} & \multirow{2}{*}{$\begin{array}{c}\% \\
13,3\end{array}$} \\
\hline \multirow{3}{*}{ Cinsiyet } & Kadın & & & \multirow{3}{*}{$\begin{array}{l}\text { Eğitim } \\
\text { Durumu }\end{array}$} & Lise & & \\
\hline & \multirow[t]{2}{*}{ Erkek } & \multirow[t]{2}{*}{156} & \multirow[t]{2}{*}{44,3} & & Lisans öğrencisi & 108 & 30,7 \\
\hline & & & & & Lisans mezunu ve üzeri & 197 & 56,0 \\
\hline \multirow{4}{*}{ Yaş } & 20 ve alt1 & 58 & 16,5 & \multirow{4}{*}{$\begin{array}{l}\text { Ailenin aylık } \\
\text { ortalama } \\
\text { geliri }\end{array}$} & $150 \$$ ve alt 1 & 59 & 16,8 \\
\hline & $21-26$ & 210 & 59,7 & & $151-400 \$$ & 163 & 46,3 \\
\hline & $27-32$ & 62 & 17,6 & & $401-700 \$$ & 86 & 24,4 \\
\hline & 33 ve üzeri & 22 & 6,3 & & $701 \$$ ve üzeri & 44 & 12,5 \\
\hline
\end{tabular}

Eğitim düzeyi açısından ise örneklemin \%56'lık (197 kişi) lisans mezunları, \%30,7'lik (108 kişi) kısmı ise lisans öğrencileri, kalan \%13,3 (47 kişi) kısmı ise lise mezunları oluşturmaktadır. Örneklemin \%46,3'ü ailesinin aylık ortalama gelirini 151-400\$ arasında olduğunu belirtilmiştir.
Katılımciların sosyal medya kullanımı ve bu sosyal medyalardaki aktivitelere katılmaları ile ilgili bilgiler Tablo 2'de gösterilmektedir.

Tablo 2. Sosyal Medya Kullanımı İle İlgili Genel Bilgiler

\begin{tabular}{|c|c|c|c|}
\hline Parametreler & Seçenekler & Frekans & $\%$ \\
\hline \multirow{4}{*}{ Sosyal Medya Kullanımı } & Facebook & 339 & 44,1 \\
\hline & Instagram & 280 & 36,5 \\
\hline & Vkontakte & 149 & 19,4 \\
\hline & Toplam & 768 & 100,0 \\
\hline \multirow{5}{*}{$\begin{array}{l}\text { Sosyal Medyadaki Aktivitelere Katılma } \\
\text { Sıklığı }\end{array}$} & Nadiren & 146 & 41,5 \\
\hline & Bazen & 137 & 38,9 \\
\hline & S1kça & 57 & 16,2 \\
\hline & Çok sık & 12 & 3,4 \\
\hline & Toplam & 352 & 100,0 \\
\hline \multirow{3}{*}{$\begin{array}{l}\text { Sosyal Medyadaki Yarışmalarda Ödül } \\
\text { Kazanma }\end{array}$} & Kazandım & 140 & 39,8 \\
\hline & Kazanmadim & 212 & 60,2 \\
\hline & Toplam & 352 & 100,0 \\
\hline \multirow{6}{*}{$\begin{array}{l}\text { Sosyal Medya Yarışmalarına Katılma } \\
\text { Nedeni }\end{array}$} & Boş vakti doldurma & 53 & 15,1 \\
\hline & Katılımdan zevk alma & 35 & 9,9 \\
\hline & Yarışmaların eğlenceli olması & 82 & 23,3 \\
\hline & Firma ve ürünleri hakkında bilgi edinme & 43 & 12,2 \\
\hline & Ödülleri kazanma & 139 & 39,5 \\
\hline & Toplam & 352 & 100,0 \\
\hline \multirow{3}{*}{$\begin{array}{l}\text { Beeline Firmasının Hizmetlerini Satın } \\
\text { Alma }\end{array}$} & Evet & 314 & 89,2 \\
\hline & Hayır & 38 & 10,8 \\
\hline & Toplam & 352 & 100,0 \\
\hline
\end{tabular}

Beeline firmasının hesaplarının bulunduğu 3 sosyal medyanın arasından Facebook en çok kullanıldığı tespit edilmiştir (\%44,1), ikinci sırada ise Instagram yer almaktadır. Katılımciların \%41,5'i sosyal medyadaki aktivitelere nadiren katıldıklarını, \%38,9'u ise bazen katıldıklarını, \%16,2'si sıkça katıldıklarını belirtmişlerdir. Katılımcıların çoğunluğunun bu tür yarışmalarda herhangi bir ödül kazanmadığı $(\% 60,2)$, ancak \%39,8'i oluşturan 140 kişinin ödül kazandığ yarışmalara katılma nedeni ödülleri kazanma ise, 82 kişinin katılma nedeni yarışmaların eğlenceli olmasıdır. Katılımcıların çoğunluğu $(\% 89,2)$ Beeline GSM operatörünün hizmetlerini kullanmaktadır. $\% 10,8$ 'i ise firmanın oyunlaştırma aktivitelerine katılsa bile onun hizmetlerini kullanmamaktadır.

Anket formunda yer alan ölçeklerin güvenirliğinin değerlendirilmesinde Cronbach Alpha katsayısından yararlanılmıştır (Tablo 3). Güvenirlik katsayısına ilişkin ölçüt değerleri aşağıdaki gibidir (Özdamar, 2002: 673).

- $0,00 \leq \alpha \leq 0,40$ : Ölçek güvenilir değildir

- $0,40 \leq \alpha \leq 0,60$ : Ölçek düşük güvenilirliktedir.

- $0,60 \leq \alpha \leq 0,80$ : Ölçek oldukça güvenilirdir.

- $\quad 0,80 \leq \alpha \leq 1,00$ : Ölçek yüksek derecede güvenilirdir.

Tablo 3. Güvenilirlik Analizi

\begin{tabular}{|l|c|c|}
\hline \multicolumn{1}{|c|}{ Faktörler } & Madde Sayıs1 & Cronbach Alpha \\
\hline 1. Oyunlaştırmaya Karşı Tutum & 5 & 0,856 \\
\hline 2. Özel Müșteri Olmak İsteği & 4 & 0,798 \\
\hline 3. Oyunlaștırma Aktivitelerinin Eğlenceli Olması & 4 & 0,774 \\
\hline 4. Müşteri Sadakati & 13 & 0,852 \\
\hline
\end{tabular}


Çalışmada kullanılan 'Oyunlaştıma aktivitelerinin eğlenceli olması' ölçeğinin Cronbach Alpha katsayısı 0,774; 'Özel müşteri olmak isteği' ölçeğinin Cronbach Alpha katsayısı ise 0,798; 'Oyunlaştımaya karşı tutum' ölçeğinin Cronbach Alpha katsayısı 0,856; 'Müşteri sadakati’ ölçeğinin Cronbach Alpha katsayısı 0,852 olarak belirlenmiştir ve bu ölçeklerin güvenilir olduğu yani ölçme hatası bulunmadığı tespit edilmiştir.

Açımlayıcı faktör analizinde temel bileşenler analizi ve varimax rotasyonu kullanılmış ve sonuçlar Tablo 4 ve 5'te özetlenmiştir.

Tablo 4. Oyunlaştırma Ölçeği Faktör Yapısı

\begin{tabular}{|c|c|c|c|c|}
\hline Boyut & Madde & Faktör Yükü & Varyans (Toplam: 63,675) & $\mathrm{KMO}$ \\
\hline \multirow{5}{*}{$\begin{array}{l}\text { Faktör 1: } \\
\text { Oyunlaştırmaya Karş1 Tutum }\end{array}$} & $\mathrm{O} 13$ & ,727 & \multirow{5}{*}{25,643} & \multirow{13}{*}{, 890} \\
\hline & $\mathrm{O} 12$ & ,568 & & \\
\hline & O11 & ,762 & & \\
\hline & $\mathrm{O} 10$ & ,793 & & \\
\hline & O9 & 760 & & \\
\hline \multirow{4}{*}{$\begin{array}{l}\text { Faktör 2: } \\
\text { Özel Müşteri Olmak İsteği }\end{array}$} & $\mathrm{O} 8$ & ,715 & \multirow{4}{*}{19,871} & \\
\hline & $\mathrm{O} 7$ & ,730 & & \\
\hline & O6 & 811 & & \\
\hline & O5 & ,656 & & \\
\hline \multirow{4}{*}{$\begin{array}{l}\text { Faktör 3: } \\
\text { Oyunlaştırma Aktivitelerinin Eğlenceli } \\
\text { Olması }\end{array}$} & $\mathrm{O} 4$ & ,508 & \multirow{4}{*}{18,162} & \\
\hline & $\mathrm{O} 3$ & ,717 & & \\
\hline & $\mathrm{O} 2$ & ,778 & & \\
\hline & $\mathrm{O} 1$ & ,693 & & \\
\hline
\end{tabular}

Tablo 4'e göre oyunlaştırma ölçeği ile ilgili açımlayıcı faktör analizi sonucunda 13 ifade için özdeğeri 1 'in üzerinde 3 faktör söz konusudur. Analiz sonucunda faktörlerin toplam varyansa yaptıkları katkının 1.faktör için \%25,643; 2.faktör için \% 19,871; 3.faktör için \% 18,162'dir. Belirlenen bu faktörlerin varyansa yaptıkları toplam katkının \%63,675 olduğu görülmektedir.

Demografik özelliklere göre oyunlaştırma aktivitelerinin algılanması değişiklik gösterip göstermediği aşağıdaki tablolarda yansıtılmıştır.

Tablo 5. Oyunlaştırma Faktörleri Ve Cinsiyet: Bağımsızlık T-Testi Sonucu

\begin{tabular}{|l|l|l|c|c|c|c|}
\hline \multicolumn{2}{|c|}{ Faktörler } & \multicolumn{2}{c|}{ Levene Testi } & \multicolumn{3}{c|}{ T-testi } \\
\cline { 3 - 7 } & & $\mathrm{f}$ & $\mathrm{p}$ & $\mathrm{t}$ & $\mathrm{df}$ & $\mathrm{P}$ \\
\hline \multirow{2}{*}{ Oyunlaştırmaya Karşı Tutum } & Equal variances assumed & 1,436 &, 232 & $-1,580$ & 350 &, 115 \\
\cline { 2 - 7 } & Equal variances not assumed & & & $-1,564$ & 317,770 &, 119 \\
\hline \multirow{2}{*}{ Özel Müşteri Olmak İsteği } & Equal variances assumed &, 000 &, 987 &,- 001 & 350 &, 999 \\
\cline { 2 - 7 } & Equal variances not assumed & & &,- 001 & 328,741 &, 999 \\
\hline $\begin{array}{l}\text { Oyunlaştırma Aktivitelerinin } \\
\text { Eğlenceli Olması }\end{array}$ & Equal variances assumed &, 219 &, 640 & $-1,105$ & 350 &, 270 \\
\cline { 2 - 7 } & Equal variances not assumed & & & $-1,109$ & 335,985 &, 268 \\
\hline
\end{tabular}

Tablo 5'de katılımcıların oyunlaştırmaya karşı tutumları $(\mathrm{t}=-1,58, \mathrm{p}>0,05)$, oyunlaştırma aracılığıyla özel müşteri olmak isteği $(\mathrm{t}=-0,01, \mathrm{p}>0,05)$ ve oyunlaştırma aktivitelerinin eğlenceli olması $(\mathrm{t}=-1,10, \mathrm{p}>0,05)$ ile cinsiyetleri arasında istatistiksel olarak anlamlı bir farklılık olmadığı görülmüştür. $\mathrm{Bu}$ testin sonucunda $\mathrm{H}_{4}, \mathrm{H}_{5}, \mathrm{H}_{6}$ hipotezleri reddedilir.

Oyunlaştırma faktörleri bakımından katılımcıların yaşlarına göre farklılık olup olmadığını tespit etmek için Anova uygulanmıştır (Tablo 6).

Tablo 6. Oyunlaştırma Faktörleri ve Yaş: Anova

\begin{tabular}{|l|c|c|}
\hline \multicolumn{1}{|c|}{ Faktörler } & F & P \\
\hline Oyunlaştırmaya Karşı Tutum & 4,450 &, 004 \\
\hline Özel Müşteri Olmak İsteği & 3,185 &, 024 \\
\hline Oyunlaştırma Aktivitelerinin Eğlenceli Olması & 4,478 &, 004 \\
\hline
\end{tabular}

Tablo 6'da görüldüğü gibi; yaş değişkenine göre oyunlaştırma düzeylerine ilişkin Anova karşılaştırılmasını gösteren dağılım incelendiğinde; oyunlaştırmaya karşı tutumları $(\mathrm{f}=4,45 \mathrm{p}<0,01)$ ve oyunlaştırma aktivitelerinin eğlenceli olması $(\mathrm{f}=4,47, \mathrm{p}<0,01)$ ile yaşları arasında istatistiksel olarak anlamlı bir farklılık olduğu; oyunlaştırma aracılığıyla özel müşteri olmak isteği $(\mathrm{f}=3,18, \mathrm{p}>0,01)$ ile yaşları arasında istatistiksel olarak anlamlı bir farklılık olmadığı görülmüştür. Bu testin sonucunda $\mathrm{H}_{7}, \mathrm{H}_{9}$ hipotezleri kabul edilmektedir, $\mathrm{H}_{8}$ hipotezi ise reddedilir. Hangi grupların farklılık gösterdiğini öğrenmek için Tukey Testinin sonuçları incelenmiştir. 
Tablo 7. Oyunlaştırma Faktörleri Ve Yaş: Tukey Testi

\begin{tabular}{|c|c|c|c|c|}
\hline Faktörler & Gruplar & Sınıf Değişkenleri & Ortalamalar Farkı & $\mathrm{P}$ \\
\hline \multirow{12}{*}{ Oyunlaştırmaya Karşı Tutum } & \multirow{3}{*}{20 ve alt 1} & $21-26$ &, 18846 & ,216 \\
\hline & & $27-32$ &,- 08857 & ,882 \\
\hline & & 33 ve üzeri &,- 15125 & ,794 \\
\hline & \multirow{3}{*}{$21-26$} & 20 ve alt1 &,- 18846 &, 216 \\
\hline & & $27-32$ &,$- 27704 *^{*}$ & 020 \\
\hline & & 33 ve üzeri &,- 33972 & ,098 \\
\hline & \multirow{3}{*}{$27-32$} & 20 ve alt1 &, 08857 & ,882 \\
\hline & & $21-26$ &, $27704 * *$ &, 020 \\
\hline & & 33 ve üzeri &,- 06268 & ,981 \\
\hline & \multirow{3}{*}{33 ve üzeri } & 20 ve alt 1 &, 15125 & ,794 \\
\hline & & $21-26$ &, 33972 & ,098 \\
\hline & & $27-32$ &, 06268 & ,981 \\
\hline \multirow{12}{*}{$\begin{array}{l}\text { Oyunlaştırma Aktivitelerinin } \\
\text { Eğlenceli Olması }\end{array}$} & \multirow{3}{*}{20 ve alt1 } & $21-26$ &, 22233 &, 141 \\
\hline & & $27-32$ &,- 01991 & ,999 \\
\hline & & 33 ve üzeri &,- 20408 & ,648 \\
\hline & \multirow{3}{*}{$21-26$} & 20 ve alt 1 &,- 22233 &, 141 \\
\hline & & $27-32$ &,- 24224 & 079 \\
\hline & & 33 ve üzeri &,$- 42641 * *$ & 034 \\
\hline & \multirow{3}{*}{$27-32$} & 20 ve altı & ,01991 & ,999 \\
\hline & & $21-26$ &, 24224 &, 079 \\
\hline & & 33 ve üzeri &,- 18416 &, 713 \\
\hline & \multirow{3}{*}{33 ve üzeri } & 20 ve alt1 & ,20408 &, 648 \\
\hline & & $21-26$ &, 42641 ** $^{*}$ &, 034 \\
\hline & & $27-32$ &, 18416 & ,713 \\
\hline
\end{tabular}

Tukey Testinin sonucunda yaş ile ilgili oyunlaştırmaya karşı tutum faktöründe 21-26 ve 27-32 yaş grupları arasında, oyunlaştırma aktivitelerinin eğlenceli olması faktöründe
21-26 ile 33 ve üzeri yaş grupları arasında anlamlı bir farklılık olduğu görülmüştür.

Bu grupların ortalamalarını Tablo 8'de incelenmiştir.

Tablo 8. Oyunlaştırma Faktörleri Ve Yaş: Tanımlayıcı İstatistikler

\begin{tabular}{|c|c|c|c|c|c|}
\hline Faktörler & Gruplar & $\mathrm{N}$ & Ortalama & Std. Sapma & Std. Hata \\
\hline \multirow{5}{*}{ Oyunlaştırmaya Karşı Tutum } & 20 ve alt1 & 58 & 3,44 & ,74 & ,097 \\
\hline & $21-26$ & 210 & 3,25 & 63 & ,043 \\
\hline & $27-32$ & 62 & 3,53 & 60 & ,076 \\
\hline & 33 ve üzeri & 22 & 3,59 & ,82 &, 175 \\
\hline & Total & 352 & 3,35 & 67 & ,036 \\
\hline \multirow{5}{*}{ Oyunlaştırma Aktivitelerinin Eğlenceli Olması } & 20 ve alt1 & 58 & 3,44 & ,75 & ,099 \\
\hline & $21-26$ & 210 & 3,22 & ,68 & , 047 \\
\hline & $27-32$ & 62 & 3,46 & ,73 &, 093 \\
\hline & 33 ve üzeri & 22 & 3,65 & ,64 & ,136 \\
\hline & Total & 352 & 3,33 & ,71 & ,038 \\
\hline
\end{tabular}

Yaş değişkenine göre katılımcıların oyunlaştırma düzeylerine ilişkin tukey testi karşılaştırılmasını gösteren dağılım incelendiğinde; 27-32 yaş grubunun, 21-26'ya göre oyunlaştırmaya karşı tutum düzeyleri daha yüksek çıkmıştır; 33 ve üzeri grubunun, 21-26'ya göre oyunlaştırma aktivitelerinin eğlenceli olarak algılama düzeyleri daha yüksek çıkmıştır.

Oyunlaştırma faktörleri bakımından katılımcıların eğitim düzeylerine göre farklılık olup olmadığını tespit etmek için Anova uygulanmıştır (Tablo 9).

Tablo 9. Oyunlaştırma Faktörleri Ve Eğitim Düzeyi: Anova

\begin{tabular}{|l|c|c|}
\hline Faktörler & $\mathrm{F}$ & $\mathrm{P}$ \\
\hline Oyunlaştırmaya Karşı Tutum &, 176 &, 839 \\
\hline Özel Müșteri Olmak İsteği &, 635 &, 530 \\
\hline Oyunlaşırma Aktivitelerinin Ĕ̆lenceli Olması &, 509 &, 601 \\
\hline
\end{tabular}

Tablo 9'da katılımcıların oyunlaştırmaya karşı tutumları $(\mathrm{f}=0,176, \mathrm{p}>0,05)$, oyunlaştırma aracılığıyla özel müşteri olmak isteği $(f=0,635, \quad p>0,05)$ ve oyunlaştırma aktivitelerinin eğlenceli olması $(f=0,509, p>0,05)$ ile eğitim düzeyleri arasında istatistiksel olarak anlamlı bir farklılık olmadığı görülmüştür. $\mathrm{Bu}$ testin sonucunda $\mathrm{H}_{10}, \mathrm{H}_{11}, \mathrm{H}_{12}$ hipotezleri reddedilir.

Katılımcıların ailelerinin ortalama aylık gelirine göre oyunlaştırma faktörleri farklılık gösterip göstermediklerini tespit etmek için Anova uygulanmıştır (Tablo 10). 
Tablo 10. Oyunlaştırma Faktörleri Ve Gelir Düzeyi: Anova

\begin{tabular}{|l|c|c|}
\hline \multicolumn{1}{|c|}{ Faktörler } & F & P \\
\hline Oyunlaşı̆rmaya Karşı Tutum & 2,168 &, 091 \\
\hline Özel Müşteri Olmak İsteği & 3,589 &, 014 \\
\hline Oyunlaşırma Aktivitelerinin Eğlenceli Olması &, 590 &, 622 \\
\hline
\end{tabular}

Tablo 10'da görüldüğü gibi; gelir değişkenine göre oyunlaştırma düzeylerine ilişkin Anova karşılaştırılmasını gösteren dağılım incelendiğinde; oyunlaştırmaya karşı tutumları $(\mathrm{f}=2,168, \mathrm{p}>0,05)$, oyunlaştırma aktivitelerinin eğlenceli olması $(\mathrm{f}=0,590, \mathrm{p}>0,05)$ ile gelir düzeyleri arasında istatistiksel olarak anlamlı bir farklılık olmadığı, oyunlaştırma aracılığıyla özel müşteri olmak isteği $(\mathrm{f}=3,589$, $\mathrm{p}<0,05)$ ile gelir düzeyleri arasında istatistiksel olarak anlamlı bir farkl1lık olduğu görülmüştür. $\mathrm{Bu}$ testin sonucunda $\mathrm{H}_{13}$ ve $\mathrm{H}_{15}$ hipotezleri reddedilir, $\mathrm{H}_{14}$ hipotezi ise kabul edilmektedir.

Oyunlaştırma aracılığıyla özel müşteri olmak isteği bakımından hangi grupların farklılık gösterdiğini öğrenmek için Tukey Testinin sonuçları (Tablo 11) incelenmiştir.

Tablo 11. Oyunlaştırma Faktörleri Ve Gelir Düzeyi: Tukey Testi

\begin{tabular}{|c|c|c|c|c|}
\hline Faktörler & Gruplar & Sınıf Değişkenleri & Ortalamalar Fark1 & $\mathrm{P}$ \\
\hline \multirow{12}{*}{ Özel Müşteri Olmak İsteği } & \multirow{3}{*}{$150 \$$ ve alt 1} & $151-400 \$$ & ,21363 & ,288 \\
\hline & & $401-700 \$$ & $35864^{*}$ &, 039 \\
\hline & & $701 \$$ ve üzeri & ,45589* &, 021 \\
\hline & \multirow{3}{*}{$151-400 \$$} & $150 \$$ ve altı &,- 21363 & ,288 \\
\hline & & $401-700 \$$ &, 14501 &, 518 \\
\hline & & $701 \$$ ve üzeri &, 24226 & ,276 \\
\hline & \multirow{3}{*}{$401-700 \$$} & $150 \$$ ve altı &,$- 35864^{*}$ &, 039 \\
\hline & & $151-400 \$$ &,- 14501 &, 518 \\
\hline & & $701 \$$ ve üzeri &, 09725 & ,911 \\
\hline & \multirow{3}{*}{$701 \$$ ve üzeri } & $150 \$$ ve altı &,$- 45589^{*}$ &, 021 \\
\hline & & $151-400 \$$ &,- 24226 & 276 \\
\hline & & $401-700 \$$ &,- 09725 & ,911 \\
\hline
\end{tabular}

Tukey Testinin sonucunda gelir ile ilgili özel müşteri olmak isteği faktöründe $150 \$$ ve altı ile 401-700\$, $150 \$$ ve altı ile 701\$ ve üzeri grupları arasında anlamlı bir farklılık olduğu görülmüştür.

Tablo 12. Oyunlaştırma Faktörleri Ve Gelir Düzeyi: Tanımlayıcı İstatistikler

\begin{tabular}{|c|l|c|c|c|c|}
\hline \multirow{2}{*}{ Faktörler } & \multicolumn{1}{|c|}{ Gruplar } & N & Ortalama & Std. Sapma & Std. Hata \\
\hline \multirow{3}{*}{ Özel Müşteri Olmak İsteği } & $150 \$$ ve altı & 59 & 3,26 &, 73 &, 095 \\
\cline { 2 - 7 } & $151-400 \$$ & 163 & 3,05 &, 76 &, 060 \\
\cline { 2 - 7 } & $401-700 \$$ & 86 & 2,90 &, 88 &, 095 \\
\cline { 2 - 7 } & $701 \$$ ve üzeri & 44 & 2,81 &, 80 &, 043 \\
\cline { 2 - 7 } & Total & 352 & 3,02 &, 80 &, 22 \\
\hline
\end{tabular}

Gelir değişkenine göre katılımcıların oyunlaştırma düzeylerine ilişkin Tukey Testi karşılaştırılmasını gösteren dağılım incelendiğinde; $150 \$$ ve altı gelir grubunun, 401$700 \$$ ve $701 \$$ ve üzeri gelir gruplarına göre oyunlaştırma aracılığı ile özel müşteri olmak isteğinin düzeyi daha yüksek çıkmıştır. Bu durumda katılımcılarda gelir seviyesi düştükçe oyunlaştırma aracılığı ile özel müşteri olmak isteğinin arttığı gözlenmektedir.
$\mathrm{Bu}$ grupların ortalamalarına bakarak, hangi grubun oyunlaştırma aracılığı ile özel müşteri olmak isteğinin düzeyinin daha yüksek olduğunu belirlenebilir (Tablo 12). 
Tablo 13'de görüldüğü üzere katılımcıların oyunlaştırma faktörleriyle müşteri sadakatine ait verilerle ilgili modelin oldukça anlamlı olduğu görülmüştür $(\mathrm{F}=54,257, \mathrm{p}=0,000$, $\mathrm{R} 2=0,344) . \quad$ Modeldeki bağımsız değișkenlerden oyunlaştırma aracılı̆̆ıyla özel müşteri olmak isteği $(\beta=0,320$, $\mathrm{p}=0,000)$ ve oyunlaştırma aktivitelerinin eğlenceli olmasi faktörünün $(\beta=0,128 \quad p<0,05)$ müşteri sadakati üzerinde anlamlı ve pozitif etkiye sahip olduğu tespit edilmiştir. $\mathrm{Bu}$ bulgulara göre $\mathrm{H}_{2}$ ve $\mathrm{H}_{3}$ hipotezleri desteklenmektedir. Buna karşın oyunlaştırmaya karşı tutumun müşteri sadakati üzerinde anlamlı bir etkiye sahip olmadığı tespit edilmiş ve $\mathrm{H}_{1}$ hipotezi reddedilmiştir $(\mathrm{p}>0,05)$.

\section{Sonuc}

Toplumsal anlamda bir internet kültürünün var olması, pazarlama faaliyetlerinin de bu yönde değişikliğe uğramasına neden olmuş, değişen ve hızla gelişen internet bakış açısı ile dijital pazarlama kavramı ortaya çıkmıştır.

Oyun unsurlarının ve oyun tasarım içeriklerinin oyun olmayan mecralarda kullanılması anlamına gelen oyunlaştırma bugün dijital pazarlamanın bir parçasıdır ve pazarlamacılar için büyük firsatlar içermektedir.

Burada önemli olan hedef kitlenin ilgisini çekebilecek kurguların yapılmasıdır. Bunun için de hedef kitleyi çok iyi tanımak, görsellik içerik ve kurgu konusunda çok iyi olmak gerekmektedir.

Kırgızistan'daki "Beeline" GSM operatörünün sosyal medya hesaplarında uyguladığı oyunlaştırmanın müşterilerin sadakati üzerindeki etkisinin incelendiği bu çalışmanın bulguları aşağıdaki gibi özetlenebilir:

- Katılımcıların büyük bir kısmı, bu tür yarışmalara ödüller kazanmak için başvurduklarını söylerken, diğerleri ise yarışmaların eğlenceli olduğunu belirtmişlerdir. Hatta \%60 gibi bir oranın yarışmaları kazanamadığı halde oynamaya devam ettiklerine bakılarak bu yarışmaların tüketiciler için gerçekten eğlenceli olduğunu görebilmek mümkündür.

Katılımcıların yaşlarına bakıldığında yaş seviyeleri yükseldikçe oyunlaştırmayı eğlenceli bulma düzeylerinin de arttığını görmekteyiz. $\mathrm{Bu}$ durum gençlerin zaten oyunla çok ilgili olup farklı oyun mecralarında oynamalarına rağmen daha yüksek yaştakilerin daha çok böyle ürün satın alma gibi durumlarda oyuna maruz kaldıkları ve bundan keyif aldıkları düşünülebilir.

- Ayrıca, katılımcılarda gelir seviyesi düştükçe oyunlaştırma aracilığı ile özel müşteri olmak isteğinin arttığ gözlenmektedir. Bu durum daha fazla miktarda satın alma yaparak özel müşteri olma şansı bulunmayan tüketicilerin oyunlaştırma ile özel müşteri olma şansı bulduklarını ve bunu önemseyen müşteriler için bir firsat olarak görüldüğünü ortaya koymaktadır.

- Araştırmada, oyunlaştırma aracılı̆̆ıly özel müşteri olmak isteği ve oyunlaştırma aktivitelerinin eğlenceli olması faktörünün müşteri sadakati üzerinde anlamlı ve pozitif etkiye sahip olduğu da tespit edilmiştir.

Oyunlaştırma, müşterinin firmaya olan sadakatini arttırmak için önemli bir araçtır. Pazarlama faaliyetlerine oyun unsurlarını ekleyerek hem sadakati, hem satış hacmini, hem de ürünlerin farklılaşmasını sağlamak mümkündür. Ancak nerede ve nasıl kullanılması gerektiğini doğru tespit edemeyen firmalar büyük masraflarla karşılaşmaktaya da belirlenen amaçlara ulaşamamaktadırlar. Örneğin, ürün hakkında bilgiyi birçok kullanıcıya göstermek isteyen bir firma, "beğen, paylaş, takip et" gibi yarışmaları oluşturabilir. Ancak unutmamalı ki, kullanıcılar bu tür yarışmalara sadece ödül kazanmak için katılabilirler. Bu durumda, firma esas amacına ulaşamayacaktır. Dolayısıyla firmalar bu konuda başarıya ulaşabilmek için müşterilerini tanımalı ve onların istekleri doğrultusunda oyunlar hazırlamalıdırlar.

Çalışma, Kırgızistan'daki Beeline GSM operatörünün takipçileri ile sınırlandırılmış, diğer firmalar kapsam dışı bırakılmıştır. Sonuçların genellenebilmesi için Kırgızistan'daki oyunlaştırmayı uygulayan diğer firmaların müşterileri üzerinde de uygulama yapılması doğru olacaktır. $\mathrm{Bu}$ çalışmada sadece dış müşterilerin katılımı sağlanmıştır. İleride yapılacak olan çalışmalarda iç müşterilerin katılımının sağlanması da önerilmektedir.

Nispeten yeni bir pazarlama aracı olduğu için oyunlaştırma üzerine yapılan çalışmaların hem firmalar hem akademisyenler için faydalı olması beklenmektedir.

\section{Kaynaklar}

Anderson, R.E. ve Srinisivan, S.S. (2003), "E-Satisfaction And E-Loyalty: A Contingency Framework", Psychology \& Marketing, 20(2), 123-138.

Bartle, R. (1996), "Hearts, Clubs, Diamonds, Spades: Players Who Suit MUDs", Journal of MUD research, 1(1), 19-58.

Bittner, J. ve Shipper, J. (2014), "Motivational Effects And Age Differences Of Gamification In Product Advertising", Journal of Consumer Marketing, 31 (5), 391 - 400.

Bozkurt, A. ve Genç-Kumtepe, E. (2014). "Oyunlaştırma, Oyun Felsefesi Ve Eğitim: Gamification”, Akademik Bilişim'14 Bildirileri, Mersin Üniversitesi, Mersin, Türkiye, 147-156.

Burke, B. (2012), "Gamification 2020: What Is The Future Of Gamification?" http://dotgroup.com.br/wpcontent/uploads/2014/04/Gartner-2020-Trends.pdf, (Son Erişim Tarihi: 15.05.2017).

Conaway, R. ve Garay, M.C. (2014), "Gamification And Service Marketing”, Springer Plus Journal, 3(653), 1-11.

Deterding, S., Dixon, D., Khaled, R. ve Nacke, L.E. (2011). "From Game Design Elements To Gamefulness: Defining "Gamification". Proceedings of the 15th International Academic MindTrek Conference: Envisioning Future Media Environments (MindTrek '11). ACM, New York, NY, USA, 9-15.

El-Khuffash, A. (2013), "Gamification”, http://elkhuffash.com/gamification/gamification_report.pdf, (Son Erişim Tarihi: 15.05.2017).

Hamari, J. ve Koivisto, J. (2015) "Social Motivations To Use Gamification: An Empirical Study Of Gamifying Exercise", ECIS 2013 Completed Research, (105), 1-12.

Huotari, K. ve Hamari, J. (2012). "Defining Gamification - A Service Marketing Perspective", Proceedings of the 16th International Academic MindTrek Conference (MindTrek '12). ACM, Tampere, Finland, 17-21.

Lucassen, G. ve Jansen, S. (2014), "Gamification In Consumer Marketing - Future Or Fallacy?", Procedia - Social and Behavioral Sciences, (148), $194-202$.

Markeeva, A. (2015), "Gamification In Business: Problems Of Application And Development Prospects", Leadership and Management, 2(3), 169-190.

Moise, D. (2013), "Gamification - The New Game In Marketing”, Romanian Journal of Marketing, (2), 29-33. 
Nicholson, S. (2012). "A User-Centered Theoretical Framework

For Meaningful Gamification", Games+Learning+Society 8.0 Kongresi, Madison, WI.

Önerli, B. (2014), “Oyunlaştırma (Gamification) Nedir?”, http://www.dijitalajanslar.com/oyunlastirma-gamification-nedir/ (Son Erişim Tarihi: 15.05.2017).

Özdamar, Kazım. (2002), Paket Programlar ile İstatistiksel Veri Analizi, 4. Basım, Eskişehir: Kaan Kitabevi.

Şahin, Ö. (2016), "Müşteri Sadakati 3.0 Ve Oyunlaştırma", Marketing Türkiye, (312), 108-109.

Tunga, Y. ve İnceoğlu, M.M. (2016). "Oyunlaştırma Tasarımı", 3. Uluslararası Eğitimde Yeni Yönelimler Konferansı Bildirileri, İzmir, Türkiye, 267-279.

Werbach, K. ve Hunter, D. (2015), For The Win: How Game Thinking Can Revolutionize Your Business. Mann, Ivanov, Ferber. Moskova.

Zichermann, G. ve Linder, J. (2014), The Gamification Revolution: How Leaders Leverage Game Mechanics To Crush The Competition. Mann, Ivanov, Ferber. Moskova. 